\title{
A PRECISION Agriculture TECHNOLOGY COURSE FOR REGIONS WITH LOWER TECHNOLOGY ADOPTION LEVELS
}

\author{
Sunil Mathanker ${ }^{1, *}$ \\ ${ }^{1}$ University of Puerto Rico at Mayagüez, Mayagüez, Puerto Rico, USA. \\ * Correspondence: sunil.mathanker@upr.edu.
}

\begin{abstract}
HighLIGHTS
- Prior and post-knowledge surveys showed that students had varied knowledge levels in the course topics.

- Knowledge gains were higher for the course topics with lower prior knowledge scores.

- Knowledge surveys can be used to adapt to the needs of the students in real-time, improve instructional material, identify effective teaching methods, and modify the course.
\end{abstract}

ABSTRACT. Precision agriculture technologies offer several benefits, and most important among them are higher farm profits and improved environmental health. The quality of precision agriculture education is one of the main barriers to the adoption of these technologies. There are studies documenting the development of precision agriculture technology courses for the world regions with higher levels of adoption. However, there are limited studies for the world regions typically characterized by lower adoption of these technologies. This study attempts to develop and teach a precision agriculture technology course for such a world region Puerto Rico, a U.S. territory. This study also consisted of collecting and analyzing the pre- and post-knowledge levels of the students attending the developed course. Using the procedure for calculation of overall grade point average, the knowledge score for each course topic was calculated from all the pre- or post-survey responses for the course topic. Additionally, the knowledge gain for each course topic was calculated by subtracting the prior knowledge score from the post knowledge score of the course topic. The results indicated that knowledge gains were higher for the course topics with the lower prior knowledge scores and were lower for the course topics with the higher prior knowledge scores. The study indicates that a prior knowledge survey can be used to adapt to the needs of the students in real-time. Likewise, a post-knowledge survey can be used to improve instructional material, identify suitable teaching methods, and modify the course. World regions with limited adoption of precision agriculture technology may begin with a precision agriculture technology course without laboratory exercises, and later add laboratory exercises as equipment becomes available and adoption level increases.

Keywords. Agricultural and environmental systems, Course development, Curriculum, Precision agriculture technologies, Student assessment.

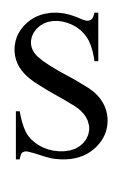
everal studies highlight the benefits of precision agriculture (PA) technologies, and the most important ones are higher farm profits and improved environmental health. Other benefits include increasing crop yields and animal performance, cost reduction, and optimization of process inputs. Stated differently, PA technologies aim to save costs, reduce environmental impact, and produce more and better food (EPRS, 2016). PA technologies may offer cost savings and higher yields through more precise management of inputs; however, they require a (C) (1) The authors have paid for open access for this article. This
NonCommercial-NoDerivatives 4.0 International License https://creative
commons.org/licenses/by-nc-nd/4.0/.
Submitted for review on 13 May 2021 as manuscript number EOPD
14669; approved for publication as a Research Article by the Education,
Outreach, \& Professional Development Community of ASABE on 11 July 2021. significant investment of capital and time (Schimmelpfennig, 2016).

Improved machinery efficiencies, reduced operator fatigue, and improved safety are the specific benefits of PA automation technologies, such as Global Positioning System/Global Navigation Satellite System (GPS/GNSS) based auto-guidance technology. Several studies have confirmed these benefits: improved environmental health by optimizing crop input application (Atherton et al., 1999), saving of crop inputs by reducing overlaps (Diekmann and Batte, 2010), reduction in operator reaction time and errors (Bashiri and Mann, 2015), and better monitoring of towed equipment and reduced operator fatigue (Bleazard et al., 2016).

A brief review of studies indicates that the economics of PA technologies and the quality of PA education are the main factors affecting the adoption of PA technologies. Access to knowledgeable change agents and the cost and 
availability of education and precision agriculture products were the reasons for the lack of adoption of precision agriculture technologies (Kitchen et al., 2002). Farm size, land quality, use of multiple precision agriculture technologies, age, education, computer use, income, and state were the factors associated with the adoption of precision agriculture technologies (Banerjee et al., 2008). Large acreage farms adopted precision agriculture technologies more than small acreage farms (Winstead et al., 2010). The adoption rate was influenced by technology, crop, and farm size (Schimmelpfennig, 2016). High levels of adoption were found among farmers who: were younger, had a higher education, were highly informed, operated large farms, and employed higher labor (Vecchio et al., 2020). Highly recognized barriers were the high initial investment of precision agriculture equipment and high learning costs (Vecchio et al., 2020). The need to increase awareness of precision agriculture tools and foster dissemination of information was felt to reduce the degree of perceived complexity (Vecchio et al., 2020).

Many studies reported developments of PA technology courses emphasizing the benefits of hands-on education. A compact variable rate sprayer for use in teaching precision agriculture was developed and field-tested (Dickinson et al., 2007). In an instrumentation and control course, hands-on skill training through laboratory exercises and class projects helped gain practical experiences for senior design and thesis research projects (Wang and Tilley, 2009). Students believed that a prototype of the variable rate sprayer improved the quality of teaching (Perez-Ruiz et al., 2011). A golf cart capable of carrying four persons safely was developed to provide improved learning opportunities to control and to learn precision agriculture technologies (Massey and Kirk, 2013). While high aptitude students were more inclined to indicate a hands-on learning style preference; low aptitude students reported greater confidence and an increased knowledge base because of the hands-on activity (Valdetero et al., 2015). A yield monitor demonstration unit capable of producing a variable yield map within a laboratory setting was developed to increase the learning opportunities and to avoid the barriers associated with field demonstrations (Massey et al., 2020).

Currently, universities and community colleges in the U.S. and elsewhere are offering programs on PA technology or offering at least one course on precision agriculture technologies (PrAg, 2021a, b). Similarly, many consultants, suppliers, and other resources are available to facilitate the use of PA technologies (PFD, 2021). However, PA educational needs, like educational needs in other areas, can vary for different world regions (Partt, 1991). In addition, the cost of PA equipment for student laboratory use (Dickinson and Johnson, 2005) can impose another constraint, and it may especially be true for the developing world regions typically characterized by low adoption of PA technologies. Furthermore, developing world regions may need to educate individuals with high competence that can compete in the globalized world and contribute to their local environment (Sepúlveda-Bustos, 2010). A comparison of an undergraduate engineering course offered in two countries showed that theoretical knowledge was emphasized in one country whereas hands-on exercises in the other country (Zhang et al., 2012).
As described above, there are studies documenting the development of precision agriculture technology courses and laboratory exercises for the world regions with higher adoption levels. However, there are limited studies documenting the development of PA technology courses for the world regions typically characterized by low adoption of PA technologies such as Puerto Rico. Anecdotally, the adoption of precision agriculture technologies in Puerto Rico can be described as low and limited to some corporate farms. Limited agriculture, small farm size, hilly terrains, cultivation of specialty crops, higher capital costs of PA technologies, and limited educational opportunities could be the possible reasons for the low adoption of precision agricultural technologies in Puerto Rico.

The University of Puerto Rico at Mayaguez (UPRM) is a land grant institution serving Puerto Rico, a U.S. territory. The UPRM College of Agriculture Sciences offers 10 undergraduate and 6 master's degree programs in agriculture including one undergraduate program in Agricultural and Environmental Systems (Spanish: Sistemas AGricolas y Ambientales, SAGA) offered by the Department of Agricultural and Biosystems Engineering where the author serves as a faculty member. Considering the PA educational needs, a course on precision agriculture technologies with laboratories ( $2 \mathrm{~h}$ of theory and $3 \mathrm{~h}$ of lab per week) was created similar to offered at many other U.S. universities. However, considering the limited availability of PA equipment and the desire among students to have the course offered without labs, the course was offered in the Spring 2020 semester without labs. The specific objective of the study was to collect and analyze the pre- and post-knowledge levels of the students attending the developed course to improve instructional materials and teaching methods.

\section{Materials ANd Methods}

The developed precision agriculture technology course was taught by the author for the first time as an elective course in the Spring 2020 semester without laboratories at the UPRM. The author had previous experience teaching other machinery courses such as an agricultural machinery course and a tractor and engine power course for more than 4 years. Additionally, the author had previous research experience in precision agriculture technologies and agricultural machinery.

The developed precision agriculture technology course was promoted in the classes taught by the author. The course was also announced through the student and faculty email distribution lists, college notice boards, and personal individual student interactions. Almost all the students attending the UPRM are Hispanics and most of them qualify for federal student grants such as the Pell grant. Out of the 16 students attending the course, 15 were Hispanics and one was African-American, 14 were male and two were female, and 15 were senior year undergraduate students of Agricultural and Environmental Systems and one was an international Soil Science graduate student. Furthermore, most of the students attending the course had previously taken at least one course with the author. 
The course syllabus consisted of 12 selected chapters from the course textbook (Shannon et al., 2018) hereafter referred to as course topics (tables 1 and 2). The students attended two $1.5 \mathrm{~h}$ lectures weekly and were required to make an oral presentation on a precision agriculture topic. The lecture presentations were developed mainly utilizing the content of the textbook chapters (Shannon et al., 2018). During the first half of the course, the lectures were delivered in person by the author using PowerPoint slides. The pdfs of the lecture presentations and textbook chapters were made available to the students at the course website. Selected short videos mostly taken from the textbook website were also shown to the students and were followed by a guided discussion. The students were also given a demonstration of a newly acquired tractor equipped with an inch-level accurate autoguidance system. The students operated the tractor with and without using the auto-guidance feature of the tractor to highlight the benefits of the auto-guidance technology.

After mid-March 2020 due to COVID-19 restrictions, the second half of the course was offered online. Narrated PowerPoint videos of the lectures were developed by the author and uploaded to the course website. The students were required to watch the lecture videos on the assigned class days for the course topic and were encouraged to ask questions to clarify doubts.

Two surveys were given to the students to determine their prior and post-knowledge levels about the course topics (tables 1 and 2). The prior knowledge survey was given in person after the students were familiarized with the course syllabus and attended an introductory lecture covering most of the course topics. The post-knowledge survey was given online because of COVID-19 restrictions and was made available on the course website during the last week of classes. Each student was asked to indicate his/her perceived knowledge level from the four choices: strongly agree, slightly agree, slightly disagree, and strongly disagree. The prior knowledge survey questions were framed like 'I know about the topic___' (table 1) and the post knowledge survey questions were framed like 'I know more about the topic than prior to attending the course' (table 2). The survey questions were adopted from the Johnson (2007) study. The student responses were anonymous, and no grade points were given for taking the surveys. Usable student responses were 12 for the prior knowledge survey and were 8 for the postknowledge survey.

Knowledge score (KS) for each course topic, like the overall grade point average (OGPA) for a student, was calculated from all the pre- or post-survey responses to the course topic survey question. The survey response 'strongly agree' indicated the highest knowledge level and was assigned 4-grade points, and the response 'strongly disagree' indicated the lowest knowledge level and was assigned 1grade point. Likewise, the response 'slightly agree' was assigned 3-grade points and the response 'slightly disagree' was assigned 2-grade points. To draw an analogy for comparison between the KS and OGPA calculation processes, the KS of a course topic will be analogous to the OGPA of a student, a course topic would be analogous to a student, and a survey response would be analogous to a course grade. For example, the survey response 'strongly agree' was

Table 1. Prior knowledge level survey, given at the beginning of the course.

\begin{tabular}{lc}
\hline & The Prior Knowledge Survey Question \\
\hline I know about Spatial and Temporal Variability & GxMxE variability \\
I know about Satellite-based Positioning Systems for Precision Agriculture & GPS/GNSS \\
I know about Yield Variability Measurement and Mapping & Yield variability \\
I know about Soil Variability Measurement and Management & Soil variability \\
I know about Pest Variability Measurement and Management & Pest variability \\
I know about Applications of Remote Sensing for Site-Specific Crop Management & Remote sensing \\
I know about Proximal Soil and Crop Sensing & Proximal sensing \\
I know about Electronics and Control Systems used in Precision Agricultural Machinery & Automation \\
I know about Precision Variable Rate Equipment & Variable-rate \\
I know about Precision Agriculture Data Management & Data management \\
I know about Environmental Implications of Precision Agriculture & Environmental implications \\
I know about Economics of Precision Farming & Economics \\
I am confident about making a Presentation on Precision Agriculture Technologies to Farmers & Presentation \\
\hline
\end{tabular}

Table 2. Post knowledge level survey, given at the completion of the course. Post Knowledge Survey Question

I know more about Spatial and Temporal Variability than prior to attending the course.

I know more about Satellite-based Positioning Systems for Precision Agriculture than prior to attending the course.

I know more about Yield Variability Measurement and Mapping than prior to attending the course.

I know more about Soil Variability Measurement and Management than prior to attending the course.

I know more about Pest Variability Measurement and Management than prior to attending the course.

I know more about Applications of Remote Sensing for Site-Specific Crop Management than prior to attending the course.

I know more about Proximal Soil and Crop Sensing than prior to attending the course.

I know more about Electronics and Control Systems used in Precision Agricultural Machinery than prior to attending the course.

I know more about Precision Variable Rate Equipment than prior to attending the course.

I know more about Precision Agriculture Data Management than prior to attending the course.

I know more about Environmental Implications of Precision Agriculture than prior to attending the course.

I know more about Economics of Precision Farming than prior to attending the course.

I am more confident about making a Presentation on Precision Agriculture Technologies to Farmers than prior to attending the course. Course Topic

Course Topic
GxMxE variability
GPS/GNSS
Yield variability
Soil variability
Pest variability
Remote sensing
Proximal sensing
Automation
Variable-rate
Data management
Environmental implications
Economics
Presentation


analogous to the course grade ' $\mathrm{A}$ ' and was assigned 4-grade points, and the survey response 'strongly disagree' was analogous to the course grade ' $\mathrm{D}$ ' and was assigned 1-grade point, and so on.

For each course topic, the pre- and post-knowledge scores were calculated using the above-described KS calculation process. Then, knowledge gain for each course topic was calculated by subtracting the prior knowledge score from the post-knowledge score. A higher knowledge score for a course topic indicates a higher knowledge level of all the students combined either at the beginning of the course or at the completion of the course. The knowledge gain for a course topic can be considered as a measure of the effectiveness of teaching methods and instructional materials used to meet the learning objectives for the course topic.

\section{RESULTS AND DISCUSSION}

The survey responses showed that the students had varied perceived knowledge levels for different course topics (fig. 1). As expected, most students rated their prior knowledge levels in the lower knowledge level categories for most of the course topics (fig. 1A). The three course topics in which most students expressed the lowest prior knowledge level 'strongly disagree' were remote sensing $(66.7 \%)$, proximal sensing $(58.3 \%)$, and variable rate technology $(58.3 \%)$. For all the course topics, an average of about $39.7 \pm 26.6 \%$ of students rated their knowledge levels in the 'strongly disagree' prior knowledge level category followed by about $38.5 \pm 14.4 \%$ in the 'slightly disagree' category. Low adoption levels, limited research studies, and the perceived complexity of these technologies may be the possible reasons for the lower prior knowledge levels. In contrast, a few students expressed their prior knowledge levels in the highest knowledge level category 'strongly agree' namely for topics: yield variability, soil variability, and presentation confidence. Anecdotally, this may be due to the following reasons: the students may have taken another course in a related course topic such as soil science or undergraduate research experience. The survey results from this study were consistent with another study (Johnson, 2007) wherein most students expressed lesser familiarity with the selected precision agriculture technologies prior to attending the precision agriculture technology course.

As a result of attending the developed course, most students indicated higher post-knowledge levels (fig. 1B). Course topics in which most students expressed the highest
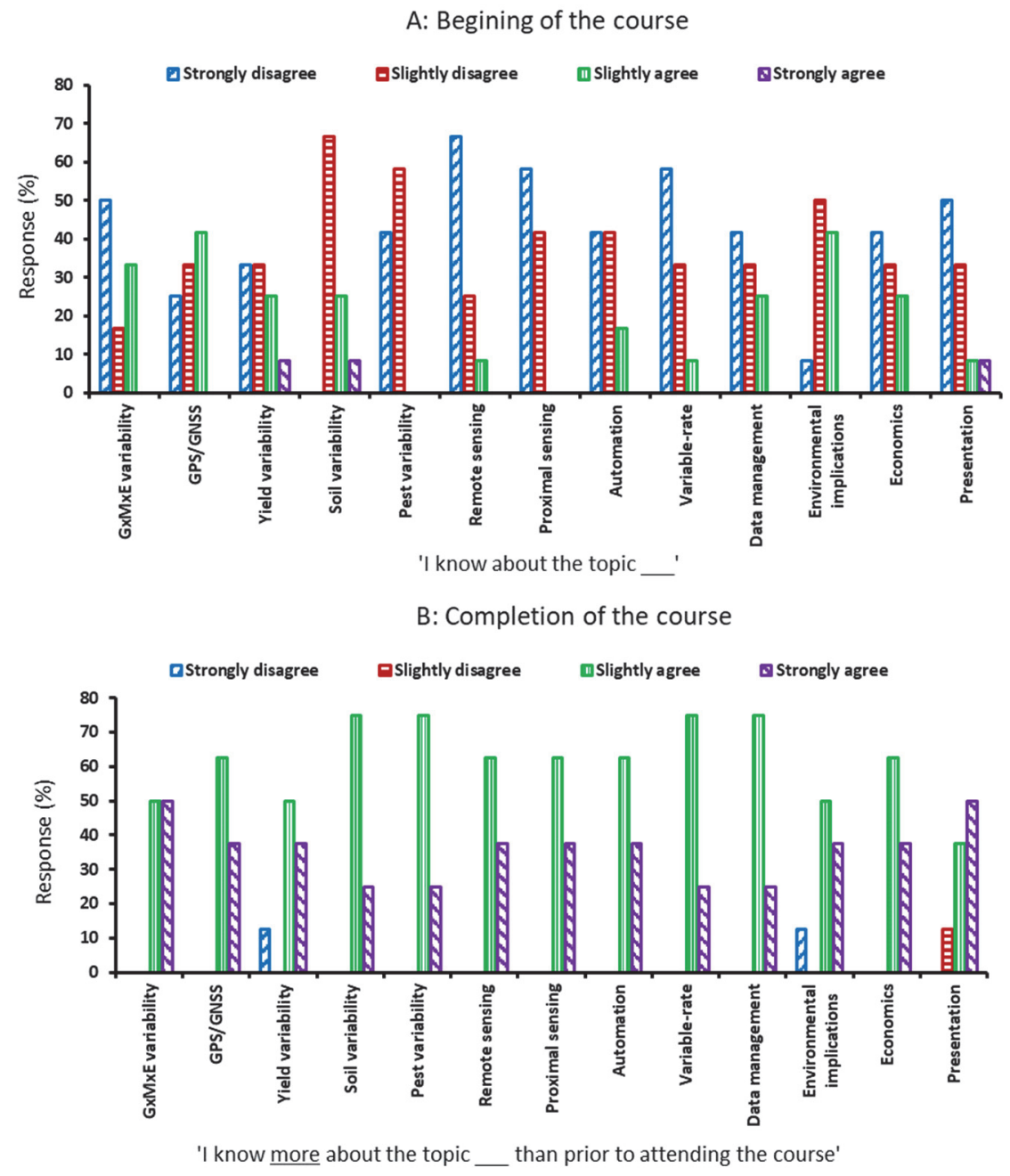

Figure 1. Student responses for the prior knowledge level survey (A) given at the beginning of the course, and the post knowledge level survey (B) given at the completion of the developed precision agriculture technology course. 
knowledge level 'strongly agree' were GxMxE (Genetics $\mathrm{x}$ Management $x$ Environment) variability $(50.0 \%)$ and presentation confidence $(50.0 \%)$. Third place $(37.5 \%)$ was shared by several course topics: GPS/GNSS, yield variability, remote sensing, proximal sensing, automation, environmental implications, and economics. For all the course topics, an average of about $35.6 \pm 8.3 \%$ of students rated their post-knowledge levels in the 'strongly agree' category followed by about $61.5 \pm 11.5 \%$ in the 'slightly agree' category. In contrast, a few students expressed their post-knowledge levels in the lower knowledge level categories: yield variability (strongly disagree, $12.5 \%$ ), environmental implications (strongly disagree, $12.5 \%$ ), and presentation confidence (slightly disagree, $12.5 \%$ ). Variations in the prior knowledge levels, student interest levels, perceived potential real-life applications, instructional methods used, and instructor preparedness levels for the different course topics may be the possible reasons for the variability in the postknowledge levels.

The knowledge gains were higher for the course topics with the lower prior knowledge scores (fig. 2). A knowledge score for a course topic indicates the average knowledge level of all the students for the course topic either at the beginning of the course or at the completion of the course. A knowledge gain for a course topic indicates the effectiveness of teaching methods and instructional materials used to meet the learning objectives of the course topic. The top three course topics in which the knowledge gains were the highest were proximal sensing (1.96), remote sensing (1.96), and variable rate technologies (1.75). It may be worthwhile to note that these course topics had the lowest prior knowledge scores: proximal sensing (1.42), remote sensing (1.42), and variable rate technologies (1.50). It may be surmised that the students may have shown greater interest in these course topics because a) they perceived their prior knowledge level as low, b) they considered these topics having greater potential real-life applications, and c) the teaching methods, instructional material, and content delivery were more effective.

In contrast, the knowledge gains were lower for the course topics with the higher prior knowledge scores (fig. 2).
The four course topics that had the lowest knowledge gains were environmental implications (0.79), soil variability (0.83), yield variability (1.04), and GPS/GNSS (1.21). Interestingly, these course topics had the highest prior knowledge scores: environmental implications (2.33), soil variability (2.42), yield variability (2.08), and GPS/GNSS (2.17). It may be inferred that the knowledge gains in these course topics were lower because a) students had higher prior knowledge levels, b) students had limited formal education in instrumentation and electronics, and these topics covered sensors and controls, c) students considered these topics having limited real-life applications, and d) the teaching methods, instructional material, and content delivery were less effective. Furthermore, the course topics environmental implications and soil variability were delivered in online mode due to COVID-19 restrictions, and a study by Carroll (2019) found that grades generally dropped for the online class compared to the traditional class.

In the author's opinion, the COVID-19 situation has adversely impacted student learning in two different ways. First, the COVID-19 situation increased the amount of teaching work for the author, and it might have adversely affected student learning. Additional work, such as recording of narrated PowerPoint videos with available moderate resources, might have reduced preparation time for the lectures and adversely affected lecture delivery. Second, the COVID-19 situation created new and unique constraints for the students that might have adversely affected student learning. The online part of the course was offered in asynchronous mode giving more flexibility to the students; however, this may have reduced their interaction time with the instructional material. Additionally, the students lacked in-person interactions with the professor and peers to clarify their misconceptions and questions. Furthermore, some students experienced poor internet connectivity and were poorly resourced. The above observations agree with the studies that reported that student learning was adversely impacted by the COVID-19 for the students who were from the least resourced schools (Gore et al., 2021) and less educated homes (Engzell et al., 2021).

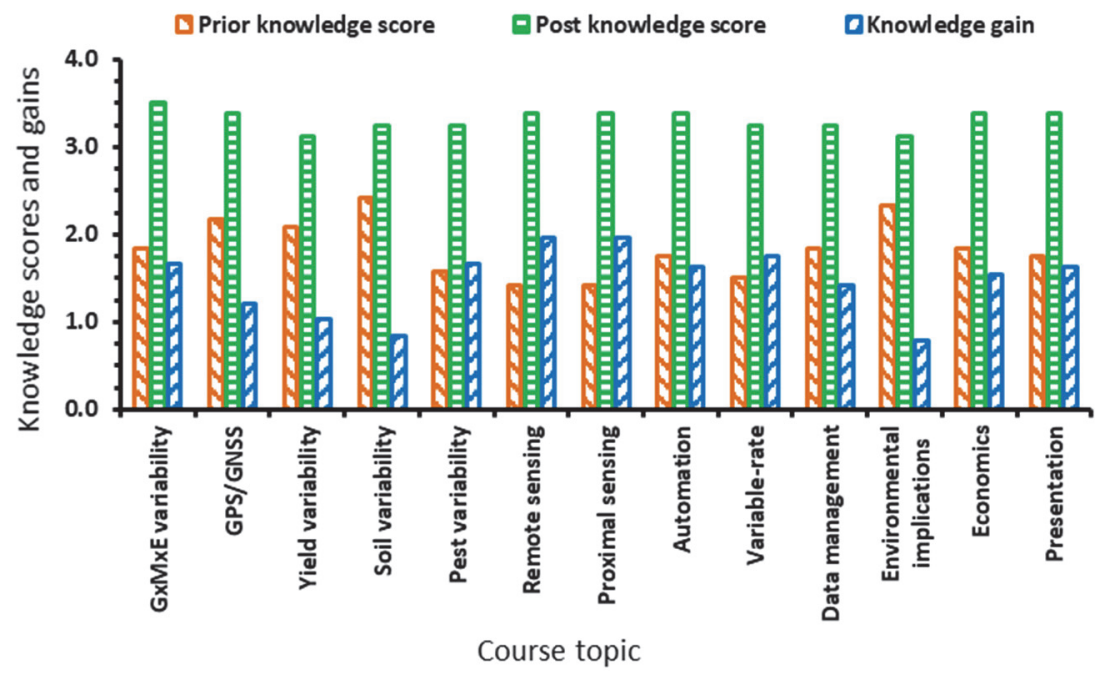

Figure 2. Mean of prior and post knowledge levels (knowledge score) and knowledge gains for the course topics of the developed precision agriculture technology course. 
The average grade point average (GPA) for the developed course was 3.27 which is comparable to the average postknowledge score of 3.31. It may be pertinent to mention that the average post-knowledge score represents the perceived knowledge levels of all the students, and the average GPA represents the evaluated knowledge levels of all the students.

The results of the prior knowledge survey can be useful to adapt to the needs of the students attending the course. For example, more basic information could be included in the course topics with lower prior knowledge scores. As a specific example, the basic information on the working of sensors and processing of digital images may be included in the proximal sensing and remote sensing course topics. Similarly, for the course topics with higher knowledge scores, such as soil and yield variability, specific case studies and data analysis exercises could be included to improve learning. It is anticipated that the results of a prior knowledge survey would be group, time, and location-specific, and may vary with the results of this study.

Similarly, a post-knowledge survey can be used to improve the instructional material, identify more suitable teaching methods, and modify the course syllabus. The survey results suggested the following actions to the author. An analysis of the content of the textbook chapter environmental implications reveals that the chapter content is more like a review article and may be more appropriate for graduate teaching and research. Improvement in teaching methods could also be explored such as adding a field trip or a documentary that highlights the environmental implications. The crop, soil, and yield sensing technologies heavily rely on geographic information systems (GIS) and an introduction to GIS may be added as a course topic. Higher knowledge gains in remote and proximal sensing indicate that soil, crop, and yield sensing could be more appropriate topics for laboratory exercises and undergraduate research.

In the author's opinion, a precision agriculture technology course without laboratory exercises may be a good starting point for the world regions with low adoption of precision agriculture technologies. It may be a better option primarily for two reasons: a) all students may not be interested in the labs, and b) lack and high cost of laboratory equipment and technology services such as GPS signal correction service and software subscriptions. Later, a separate laboratory course may be developed for interested students and may be offered less frequently than the theory course. Furthermore, when the adoption level improves, and need is felt laboratory exercises could be integrated with the theory course.

\section{Conclusions}

The prior and post-knowledge surveys showed that the student knowledge levels varied for different course topics. GPS/GNSS, soil variability, and environmental implications were the course topics in which students expressed higher prior knowledge levels. Whereas GxMxE variability, precision agriculture economics, and presentation skills were the course topics in which the students expressed higher postknowledge levels. The knowledge gains were higher for the course topics with lower prior knowledge scores. In contrast, the knowledge gains were lower for the course topics with higher prior knowledge scores. A prior knowledge survey can be used to adapt to the needs of the students in real-time. Similarly, a post-knowledge survey can be used to improve the instructional material, identify effective teaching methods, and modify the course syllabus. World regions with limited adoption of precision agriculture technology may begin with a precision agriculture technology course without laboratory exercises. Later on, add laboratory exercises as equipment becomes available and the adoption level increases.

\section{ACKNOWLEDGMENTS}

The author would like to thank all the students attending the Precision Agriculture Technology course and the department faculty for their valuable input and support during this study. The study was funded by NIFA award number 201870004-28681: 'Strengthen Puerto Rico's Agricultural Sciences Programs by Integrating Precision Agriculture Technologies.'

\section{REFERENCES}

Atherton, B. C., Morgan, M. T., Shearer, S. A., Stombaugh, T. S., \& Ward, A. D. (1999). Site-specific farming: A perspective on information needs, benefits and limitations. JSWC, 54(2), 455461.

Banerjee, S., Martin, S. W., Roberts, R. K., Larkin, S. L., Larson, J. A., Paxton, K. W.,... Reeves, J. M. (2008). A binary logit estimation of factors affecting adoption of gps guidance systems by cotton producers. J. Agric. Appl. Eco., 40(1), 345-355. https://doi.org/10.1017/S1074070800023646

Bashiri, B., \& Mann, D. D. (2015). Impact of automation on drivers' performance in agricultural semi-autonomous vehicles. JASH, 21(2), 129-139. https://doi.org/10.13031/jash.21.10977

Bleazard, T., Pate, M. L., Lawver, R. G., Israelsen, C., \& Hatch, R. (2016). Farmers' perceptions on the utility of auto-guidance technology to improve operator safety. ASABE Paper No. 162457078. St. Joseph, MI: ASABE.

Carroll, N. J. (2019). Environmental systems management: from lecture to flipped. ASABE Paper No. 1900048. St. Joseph, MI: ASABE.

Dickinson, A. R., \& Johnson, D. M. (2005). A low-cost programmable logic control (PLC) trainer for use in a university agricultural electricity course. ASAE Paper No. 058013. St. Joseph, MI: ASAE.

Dickinson, A. R., Johnson, D. M., \& Wardlow, G. W. (2007). A compact variable rate sprayer for teaching precision agriculture. Appl. Eng. Agric., 23(3), 267-272. https://doi.org/10.13031/2013.22679

Diekmann, F., \& Batte, M. T. (2010). Ohio farming practices survey: Adoption and use of precision farming technology in Ohio. Report by Agricultural, environmental and development economics, Ohio State University Extension, Report Series AEDE-RP-0129-10.

Engzell, P., Frey, A., \& Verhagen, M. D. (2021). Learning loss due to school closures during the COVID-19 pandemic. Proc. Natl. Academy Sci., 118(17), e2022376118. https://doi.org/10.1073/pnas.2022376118 
EPRS. (2016). Precision agriculture and the future of farming in Europe. Scientific Foresight Study, PE 581.892:

IP/G/STOA/FWC/2013-1/Lot 7/SC5. Brussels, Belgium: European Parliament Research Service. Retrieved from http://www.ep.europa.eu/stoa/

Gore, J., Fray, L., Miller, A., Harris, J., \& Taggart, W. (2021). The impact of COVID-19 on student learning in New South Wales primary schools: An empirical study. Australian Educational Res. 10.1007/s13384-021-00436-w

Johnson, D. M. (2007). Integrating precision technologies into a mechanized systems management course. ASABE Paper No. 078035. St. Joseph, MI: ASABE.

Kitchen, N. R., Snyder, C. J., Franzen, D. W., \& Wiebold, W. J. (2002). Educational needs of precision agriculture. Precis. Agric., 3(4), 341-351. https://doi.org/10.1023/A:1021588721188

Mathanker, S. K. 2021. Developing a precision agriculture technology course for regions with lower technology adoption levels. ASABE Meeting Paper No. 2100475. St. Joseph, MI: ASABE.

Massey, H. F., \& Kirk, K. R. (2013). Teaching precision agriculture technology with modified diesel golf cart. ASABE Paper No. 131620550. St. Joseph, MI: ASABE.

Massey, H. F., DiBenedetto, C. A., \& Quinney, S. A. (2020). Teaching precision agriculture technology with a grain yield demonstration unit. ASABE Paper No. 2001414. St. Joseph, MI: ASABE. https://doi.org/10.13031/aim.202001414

Perez-Ruiz, M., Rodriguez-Lizana, A., Carballido, J., Aguera, J., \& Pelegrin, F. (2011). A compact variable rate sprayer for teaching precision agriculture. Appl. Eng. Agric., 54(6), 2353-2360. https://doi.org/10.13031/2013.40635

PFD. (2021). Precision Ag technology talent \& training network (PATTN). Precision Farming Dealer. Retrieved from https://www.precisionfarmingdealer.com/directories/114precision-ag-technology-talent-training-network-pattn

PrAg, Precision Ag. (2021a). Top 20 two-year colleges for precision agriculture. Retrieved from https://www.precisionag.com/market-watch/top-20-two-yearcolleges-for-precision-agriculture/\#Tinsel/61696/20
PrAg, Precision Ag. (2021b). 25 Best colleges for precision agriculture. Retrieved from

https://www.precisionag.com/market-watch/25-best-collegesfor-precision-agriculture/

Pratt, D. D. (1991). Conceptions of self within China and the United States: Contrasting foundations for adult education. Int. J. Intercultural Relations, 15(3), 285-310. https://doi.org/10.1016/0147-1767(91)90003-Y

Schimmelpfennig, D. (2016). Farm profits and adoption of precision agriculture, ERR-217. Washington, DC: USDA, ERS.

Sepulveda-Bustos, E. S. (2010). Teaching and learning with information technology: The challenge of globalization for Latin America and the Caribbean. ASABE Paper No. 1008956. St. Joseph, MI: ASABE.

Shannon, D. K., Clay, D. E., \& Kitchen, N. R. (2018). Precision agriculture basics. Madison, WI: ASA, CSSA, SSSA.

Valdetero, H. E., Kirk, K. R., Dobbins, T. R., \& Fravel, P. M. (2015). Teaching small engine diagnostics using mobile app technology. ASABE Paper No. 152190040. St. Joseph, MI: ASABE.

Vecchio, Y., Agnusdei, G. P., Miglietta, P. P., \& Capitanio, F. (2020). Adoption of precision farming tools: The case of Italian farmers. Int. J. Environ. Res. Public Health, 17(3), 869. https://doi.org/10.3390/ijerph17030869

Wang, N., \& Tilley, D. (2009). Involvement of practical projects in undergraduate and graduate teaching. ASABE Paper No. 096221. St. Joseph, MI: ASABE.

Winstead, A. T., Norwood, S. H., Griffin, T. W., Runge, M., Adrian, A. M., Fulton J., P., \& Kelton, J. (2010). Adoption and use of precision agriculture technologies by practitioners. Proc. 10th Int. Conf. on Precision Agriculture.

Zhang, Y., Yang, C., Li, L., \& Wang, N. (2012). A comparison of instructional methods on computer-aid design used in China and United States universities. ASABE Paper No. 121337973. St. Joseph, MI: ASABE. 